\title{
Intermediate Progenitors in Adult Hippocampal Neurogenesis: Tbr2 Expression and Coordinate Regulation of Neuronal Output
}

\author{
Rebecca D. Hodge, ${ }^{1}$ Thomas D. Kowalczyk, ${ }^{1}$ Susanne A. Wolf, ${ }^{2}$ Juan M. Encinas, ${ }^{3}$ Caitlin Rippey, ${ }^{1}$ Grigori Enikolopov, ${ }^{3}$ \\ Gerd Kempermann, ${ }^{2}$ and Robert F. Hevner ${ }^{1}$ \\ ${ }^{1}$ Departments of Neurological Surgery and Pathology, University of Washington School of Medicine, Seattle, Washington 98101-1304, ${ }^{2}$ Max Delbrück \\ Center for Molecular Medicine, 13125 Berlin, Germany, and ${ }^{3}$ Cold Spring Harbor Laboratory, Cold Spring Harbor, New York 11724
}

\begin{abstract}
Neurogenesis in the adult hippocampus is a highly regulated process that originates from multipotent progenitors in the subgranular zone (SGZ). Currently, little is known about molecular mechanisms that regulate proliferation and differentiation in the SGZ. To study the role of transcription factors (TFs), we focused on Tbr2 (T-box brain gene 2), which has been implicated previously in developmental glutamatergic neurogenesis. In adult mouse hippocampus, Tbr2 protein and Tbr2-GFP (green fluorescent protein) transgene expression were specifically localized to intermediate-stage progenitor cells (IPCs), a type of transit amplifying cells. The Tbr2 + IPCs were highly responsive to neurogenic stimuli, more than doubling after voluntary wheel running. Notably, the Tbr2+ IPCs formed cellular clusters, the average size of which (Tbr2 + cells per cluster) likewise more than doubled in runners. Conversely, Tbr2+ IPCs were selectively depleted by antimitotic drugs, known to suppress neurogenesis. After cessation of antimitotic treatment, recovery of neurogenesis was paralleled by recovery of Tbr2 + IPCs, including a transient rebound above baseline numbers. Finally, Tbr2 was examined in the context of additional TFs that, together, define a TF cascade in embryonic neocortical neurogenesis (Pax6 $\rightarrow$ Ngn2 $\rightarrow$ Tbr2 $\rightarrow$ NeuroD $\rightarrow$ Tbr1). Remarkably, the same TF cascade was found to be linked to stages of neuronal lineage progression in adult SGZ. These results suggest that Tbr2+ IPCs play a major role in the regulation of adult hippocampal neurogenesis, and that a similar transcriptional program controls neurogenesis in adult SGZ as in embryonic cerebral cortex.
\end{abstract}

Key words: transcription factor; dentate gyrus; transit amplifying cells; glutamatergic neurons; subgranular zone; type-2 cells

\section{Introduction}

Adult hippocampal neurogenesis is a constitutive but highly regulated process that occurs in a neurogenic niche, the subgranular zone (SGZ) of the dentate gyrus (DG). Progenitors in the SGZ produce glutamatergic neurons that populate the granule cell layer (GCL) of the DG (Kempermann et al., 2004b). Primary progenitor cells (type-1), characterized by GFAP and nestin expression, exhibit morphology typical of radial glia and divide slowly to produce intermediate progenitor cells (IPCs), a type of transit amplifying cell (Filippov et al., 2003; Kempermann et al., 2004b; Steiner et al., 2004, 2006). Undifferentiated IPCs (type-2a and type-2b) divide rapidly to produce neuronal committed IPCs (type-3) and are responsive to stimuli that affect neuron production in the DG (van Praag et al., 1999; Steiner et al., 2004; Jessberger et al., 2005; Encinas et al., 2006). Type-3 IPCs generate

Received Sept. 18, 2007; revised Jan. 21, 2008; accepted Feb. 23, 2008.

This work was supported by National Institutes of Health Grant R01 NS050248 (R.F.H.) and Heart and Stroke Fund of Canada Research Fellowship (R.D.H.). We thank Drs. David Anderson and Samuel Pleasure for providing antibodies and Dr. Philip Horner for helpful suggestions on experimental design. We thank Ray Anthony M. Daza for technical assistance.

Correspondence should be addressed to Robert F. Hevner, Seattle Children's Hospital Research Institute, Room 828, 1900 Ninth Avenue, Seattle, WA 98101-1304. E-mail: rhevner@u.washington.edu.

DOI:10.1523/JNEUROSCI.4280-07.2008

Copyright $\odot 2008$ Society for Neuroscience $\quad$ 0270-6474/08/283707-11\$15.00/0 immature neurons, and those neurons that survive through an experience-dependent regulatory period integrate into the GCL as mature granule cells within 1 month (Kempermann et al., 2004b; Tashiro et al., 2007). The functional significance of adult neurogenesis is currently not well understood. However, studies have correlated DG neurogenesis with cognitive function, memory, neurodegenerative diseases, and depression (Kempermann et al., 2004a; Emsley et al., 2005; Encinas et al., 2006; Ernst et al., 2006).

Interestingly, neurogenesis in the adult brain recapitulates some aspects of neurogenesis in the developing brain (Pleasure et al., 2000; Espósito et al., 2005; Nacher et al., 2005; Song et al., 2005; Hevner et al., 2006), suggesting that progenitor cells in the embryonic and adult brain may share similar molecular phenotypes. In the developing brain, transcription factor (TF) cascades (sequential expression of multiple TFs) are involved in controlling progenitor proliferation and specifying neuron identity and neurotransmitter fate (Arlotta et al., 2005; Wang and Harris, 2005; Hevner, 2006; Guillemot, 2007). However, the role of TFs in adult neurogenesis, with a few exceptions (Shi et al., 2004; Maekawa et al., 2005; Shen et al., 2006), remains primarily unknown. To better understand the molecular mechanisms regulating neurogenesis in the DG, we focused on characterizing the expression of Tbr2, a T-domain TF previously reported to act as 
part of a cascade regulating glutamatergic neuron production during cortical development (Englund et al., 2005). In this TF cascade, Pax6 + radial glia produce IPCs that express Tbr2, which then divide to produce NeuroD + neuroblasts that differentiate into Tbr1+ cortical neurons (Haubensak et al., 2004; Miyata et al., 2004; Noctor et al., 2004; Englund et al., 2005). Ngn2, a proneural TF shown to be regulated by Pax6 in the embryonic cortex (Heins et al., 2002; Scardigli et al., 2003), precedes Tbr2 expression in this TF cascade. The present experiments were designed to determine whether aspects of this TF cascade are conserved in the adult DG and to examine the identity of Tbr2+ cells in the SGZ. Experiments were also conducted to assess the responses of Tbr2 + cells to neurogenic stimuli, with the goal of understanding how Tbr2+ IPCs contribute to neuron production in the adult DG.

\section{Materials and Methods}

Animals. Wild-type C57BL/6 mice were purchased from The Jackson Laboratory (Bar Harbor, ME) or Charles River Laboratories (Wilmington, MA). Tbr2-GFP (green fluorescent protein) mice were obtained from the GENSAT Project (Gong et al., 2003) and maintained on a CD1 background. The generation of transgenic reporter nestin-GFP mice was described previously (Mignone et al., 2004). Animals were housed under standard conditions ( $12 \mathrm{~h}$ light/dark cycle), and all experimental procedures were approved by the University of Washington Institutional Animal Care and Use Committee. All animals used were 3-5 months of age, unless otherwise indicated.

Histology and immunohistochemistry. Animals were deeply anesthetized with Avertin and perfused with cold, buffered 4\% paraformaldehyde in $0.1 \mathrm{M}$ phosphate buffer. Brains were postfixed for $2 \mathrm{~h}$ or overnight at $4^{\circ} \mathrm{C}$ and transferred to $30 \%$ sucrose overnight at $4^{\circ} \mathrm{C}$. For acute bromodeoxyuridine (BrdU) labeling, 5-month-old C57BL/6 mice were injected intraperitoneally with BrdU $(100 \mu \mathrm{g} / \mathrm{g}$ in $0.9 \%$ saline; SigmaAldrich, St. Louis, MO) and perfused $2 \mathrm{~h}$ postinjection. Tissues were sectioned coronally at $40 \mu \mathrm{m}$ on a sliding microtome and stored at $-20^{\circ} \mathrm{C}$ in cryoprotectant solution or sectioned sagittally at $12 \mu \mathrm{m}$ on a cryostat, mounted on Superfrost Plus glass slides (Thermo Fisher Scientific, Waltham, MA), and stored at $-80^{\circ} \mathrm{C}$.

Immunohistochemical analyses were performed as described previously (Englund et al., 2005). Briefly, sections were boiled in $10 \mathrm{~mm}$ sodium citrate, $\mathrm{pH} 6.0$, and blocked in $10 \%$ normal serum, $0.1 \%$ Triton X-100 (Sigma-Aldrich), and 2\% bovine serum albumin (Sigma-Aldrich) for $1 \mathrm{~h}$ at room temperature. Incubation with primary antibodies was performed at $4^{\circ} \mathrm{C}$ overnight. Secondary antibodies were applied to sections for $2 \mathrm{~h}$ at room temperature. All primary antibodies used in the present studies are listed in Table 1. Secondary antibodies were conjugates of Alexa Fluor 488, Alexa Fluor 594, and Alexa Fluor 647 (1:200; Invitrogen, Carlsbad, CA). TO-PRO-3 iodide (0.1 $\mu \mathrm{M}$; Invitrogen) and DAPI ( $4^{\prime}, 6^{\prime}$-diamidino-2-phenylindole) $(0.01 \%$; Invitrogen $)$ were used as nuclear counterstains.

Confocal microscopy and antigen colocalization. To quantitatively examine colocalization of Tbr 2 with antigens of interest, every twentieth 12 $\mu \mathrm{m}$ section or every sixth $40 \mu \mathrm{m}$ section (six to eight sections per animal in both cases) through the rostrocaudal extent of the dentate gyrus was double immunostained. Optical sections $(0.4-1 \mu \mathrm{m})$ were collected using a Bio-Rad (Hercules, CA) LS200 confocal microscope with $1.3 \mathrm{nu}-$ merical aperture (N.A.), $40 \times$, or 1.4 N.A, $60 \times$ oil objectives through at least 50 randomly selected cells per animal ( $n=3$ mice), and the pheno- types of these cells were assessed as described previously (van Praag et al., 1999; Kronenberg et al., 2003). Three-dimensional reconstructions and orthogonal views were prepared using Axiovision Inside4D software (Zeiss, Thornwood, NY). Images were adjusted for contrast, brightness, and color using Adobe Photoshop CS2 (Adobe Systems, Mountain View, CA).

BrdU pulse chase experiments. Three-month-old female C57BL/6 mice were injected with a single pulse of $\mathrm{BrdU}$ (100 $\mu \mathrm{g} / \mathrm{g}$ body weight) and randomly assigned to different survival time points. Animals were perfused at survival time points $2 \mathrm{~h}, 24 \mathrm{~h}, 3 \mathrm{~d}$, and $7 \mathrm{~d}$ after BrdU administration ( $n=3$ animals per time point) as described previously (Kronenberg et al., 2003). Brains were sectioned at $40 \mu \mathrm{m}$, and every sixth section was triple labeled for BrdU, Tbr2, and Sox2. An adjacent one-in-six series was selected from each brain and triple labeled for BrdU, Tbr2, and Doublecortin (DCX). The phenotypes of BrdU-positive cells were assessed by collecting confocal z-stacks using a $60 \times 1.4$ N.A. oil objective through all BrdU-labeled cells in the GCL and examining these cells for coexpression of the other markers listed above. Results are presented as the fraction of labeled cells to the total number of BrdU-positive cells. Unidentified cells refer to BrdU-positive cells that did not coexpress other assessed antigens.

Running experiments. Eight-week-old female C57BL/6 mice were randomly assigned to standard housing [control (CTR), $n=4$; CTR 14 weeks, $n=4$ ] or cages with a running wheel (RUN) as described previously (van Praag et al., 1999; Kronenberg et al., 2003). Mice in the RUN group had voluntary access to the wheel for $10 \mathrm{~d}$. BrdU $(50 \mu \mathrm{g} / \mathrm{g})$ was given at the end of the running period, and mice were perfused $1 \mathrm{~d}$ (RUN, $n=4$ ) or 4 weeks later (RUN $28 \mathrm{~d}, n=4$ ). Control mice were age matched to each running group and were perfused at 10 weeks of age (CTR) and 14 weeks of age (CTR 14 weeks) for comparison with the RUN and RUN 28 d groups, respectively. Total cell number counts (Tbr2+ and Tbr2+/BrdU+) were conducted using an AxioImager.Z1 epifluorescence microscope and Axiovision 4.6 software (Zeiss) with a modified stereological procedure, where cells were excluded from counts if they intersected the top focal plane of the section, as described previously (Williams and Rakic, 1988; van Praag et al., 1999; Kronenberg et al., 2003). Cells were counted on every sixth $40 \mu \mathrm{m}$ coronal section through the DG, and the sum of these counts was multiplied by six to generate estimates of absolute numbers. Statistical analyses of Tbr $2+$ cells were conducted using ANOVA with Tukey's honestly significant difference post hoc test (SPSS, Chicago, IL). Comparisons of Tbr $2+/ \mathrm{BrdU}+$ cells excluded the RUN 28 d group, because no double-labeled cells were 




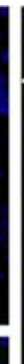
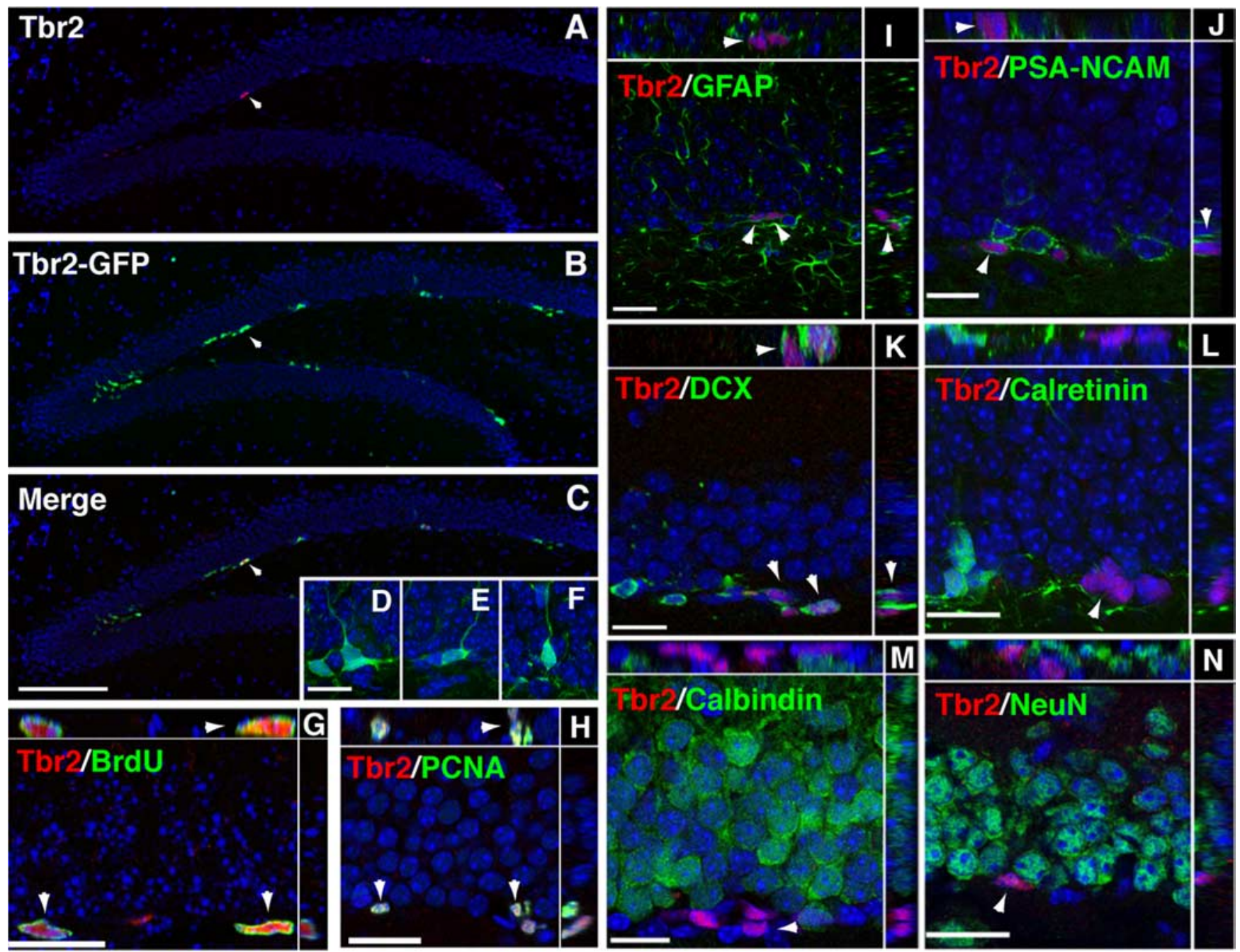

Figure 1. Tbr2 expression in the adult DG. $\boldsymbol{A}$, Tbr2 protein was restricted to cells in the SGZ (arrowhead). $\boldsymbol{B}$, Tbr2-GFP expression was strongest in clustered cells in the SGZ (arrowheads) and also apparent in the inner GCL. C, Merged images showed that the majority of Tbr2-positive cells also expressed Tbr2-GFP (arrowhead); however, Tbr2-GFP expression was more widespread than Tbr2 protein expression. $\boldsymbol{D}-\boldsymbol{F}$, Cells expressing Tbr2-GFP had diverse morphologies, some with tangentially oriented cell bodies typical of type-2 cells $(\boldsymbol{D})$ and some with processes extending into the $G C L$ similar to immature neurons $(\boldsymbol{E}, \boldsymbol{F}) . \boldsymbol{G}, \boldsymbol{H}, \mathrm{Tbr} 2+$ cells proliferated in the SGZ as shown by colabeling with acute BrdU ( $\boldsymbol{G}$, arrowhead) and PCNA ( $\boldsymbol{H}$, arrowhead). Orthogonal views of double-labeled nuclei through the $x$-z and $y$-z axes of confocal stacks are separated by white lines in $\mathbf{G}-N$. $I$, GFAP-positive processes were typically observed to surround Tbr2 + cells, but the cellular origin of these processes was difficult to discern (arrowheads). $\boldsymbol{J}, \boldsymbol{K}, \mathrm{Tbr} 2+$ cells colocalized with some PSA-NCAM and DCX + cells, but expression was low in double-labeled cells ( $\boldsymbol{J}, \boldsymbol{K}$, arrowheads), which were often surrounded by DCX + or PSA-NCAM + single-labeled cells. $L$, Tbr2 protein did not colocalize with calretinin. $\boldsymbol{M}, \boldsymbol{N}$, Tbr2 protein did not colocalize with either of the mature granule cell markers calbindin or NeuN. Scale bars: (in C) $\boldsymbol{A}-\boldsymbol{C}, 100 \mu \mathrm{m}$; (in $\boldsymbol{D}) \boldsymbol{D}-\boldsymbol{F}, 15 \mu \mathrm{m} ; \boldsymbol{G}, 15 \mu \mathrm{m} ; \boldsymbol{H}-\boldsymbol{N}, 20 \mu \mathrm{m}$.

observed, and used Student's $t$ test. Significance was achieved at a level of $p<0.05$.

Cluster analysis. Cell cluster size was determined in RUN and CTR mice. Clusters were defined as groups of Tbr2 + cells in the SGZ wherein individual cells were separated by $<1.5$ cell diameters $(15 \mu \mathrm{m})$ from their nearest neighbor. Cells separated by $>1.5$ cell diameters were counted as separate clusters. Average cell diameter was determined in both groups by measuring the length of the cells across their longest axis using Axiovision 4.6 software (Zeiss). At least 50 randomly selected Tbr $2+$ cells per animal were measured ( $n=4$ animals/group), and there was no significant difference between groups. Clusters were counted in every sixth 40 $\mu \mathrm{m}$ coronal section ( $n=4$ animals/group) and compared using Student's $t$ test.

Antimitotic treatment. Three-month-old C57BL/6 mice were given $1.5 \%$ Cytosine $\beta$-D-arabinofuranoside (Sigma-Aldrich) dissolved in $0.9 \%$ saline via an osmotic minipump for $7 \mathrm{~d}$ (model 1007D; Alzet, Cupertino, CA) at stereotaxic coordinates described previously (Seri et al., 2001, 2004). Procarbazine $(0.25 \mathrm{mg} / \mathrm{ml}$; Sigma-Tau Pharmaceuticals, Gaithersburg, MD) was given concurrently in drinking water. Shamoperated controls $(n=3)$ were implanted with pumps containing $0.9 \%$ saline and given normal drinking water. Intact controls $(n=4)$ were unoperated age-matched mice. Survival times were $0,2,5,15$, and $30 \mathrm{~d}$ after withdrawal of drug treatment $(n=4$ for all groups, except $n=3$ for $15 \mathrm{~d}$ group). At each time point, mice were given two BrdU injections (50 $\mu \mathrm{g} / \mathrm{g}) 12 \mathrm{~h}$ apart, with the last injection given $2 \mathrm{~h}$ before perfusion, as described previously (Seri et al., 2004). Absolute cell numbers were quantified using a modified stereological procedure and statistically analyzed using ANOVA as described above (Williams and Rakic, 1988; van Praag et al., 1999; Kronenberg et al., 2003).

\section{Results}

Morphology and proliferation of Tbr2 + cells

Tbr2 protein expression was restricted to the SGZ of the DG and was not present in any other regions of the hippocampus (Fig. $1 A, C)$. Tbr2-GFP transgene expression was prominent in the SGZ and also apparent in some cells in the inner portion of the GCL (Fig. $1 B, C$ ). The number of Tbr2-GFP+ cells was consistently higher than the number of Tbr $2+$ cells, likely as a result of GFP perdurance. In both cases, cells expressing Tbr2 were typi- 


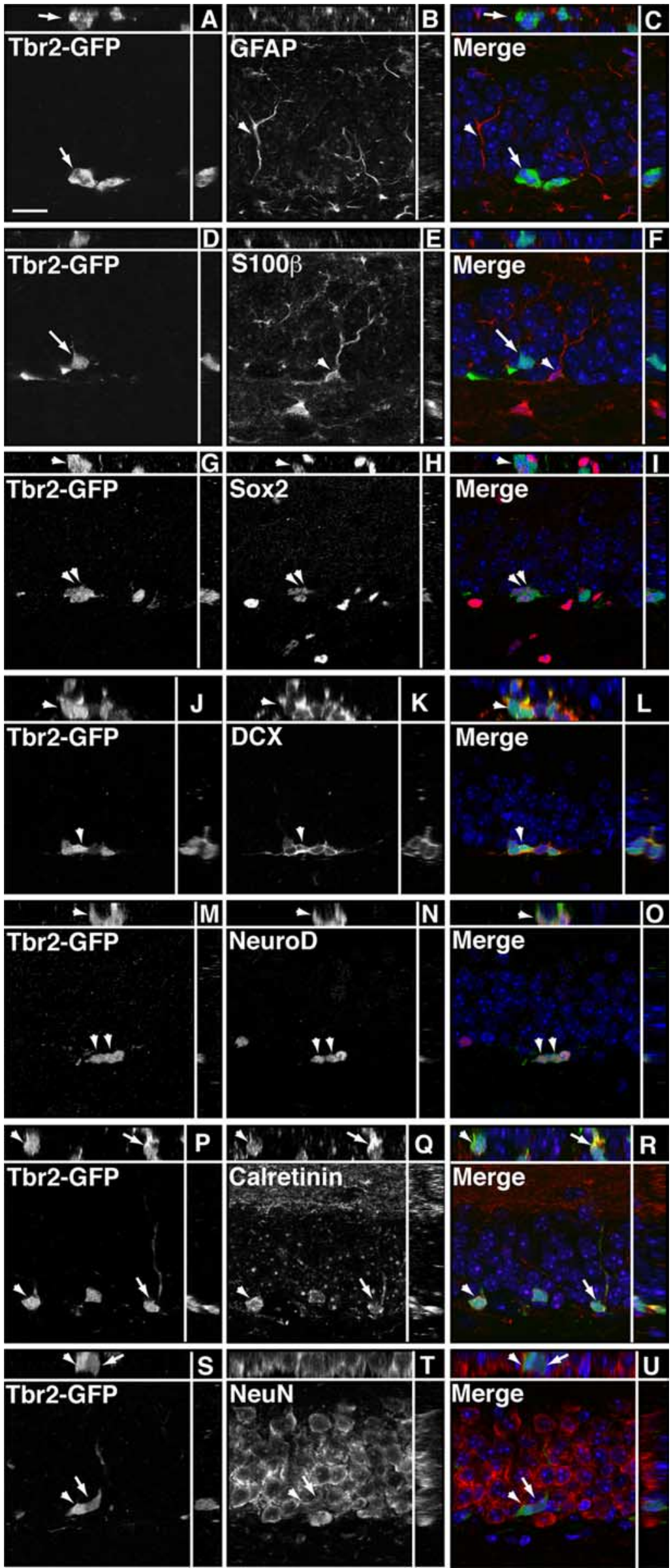

cally found in clusters in the SGZ (Fig. $1 A-$ $C)$. Tbr2-GFP expression revealed the morphology of Tbr $2+$ cells, most of which exhibited short processes tangentially oriented to the GCL (Fig. 1D). In some cases, Tbr2-GFP + cells with morphology suggestive of newly born neurons and long processes oriented toward the GCL were observed (Fig. 1D-F).

To examine the proliferation of Tbr2+ cells, animals were injected with BrdU $(100 \mu \mathrm{g} / \mathrm{g})$ and killed $2 \mathrm{~h}$ postinjection (Fig. $1 G$ ). Counts of Tbr $2+/ \mathrm{BrdU}+$ cells showed that $34.4 \pm 5.4 \%$ (mean \pm SEM) of Tbr2+ cells in the SGZ were BrdU+, indicating that a significant proportion were in S phase. Additionally, Tbr2+ cells accounted for $75.97 \pm 5.86 \%$ of these BrdU + cells, suggesting that Tbr2 + cells represent a large majority of rapidly dividing cells in the SGZ. As well, 92.6 $\pm 3.8 \%$ of Tbr $2+$ cells colocalized with proliferating cell nuclear antigen (PCNA), indicating that the vast majority of Tbr2+ cells were mitotically active (Fig. $1 \mathrm{H}$ ). In total, $55.64 \pm 3.95 \%$ of PCNA + cells were correspondingly Tbr2+, suggesting that Tbr + cells may account for half or more of the total dividing progenitor population in the SGZ. (For a summary of the quantitative data from these and related colocalization experiments, see Fig. $4 S$.)

Characterization of Tbr $2+$ cells in the SGZ

The phenotype of Tbr $2+$ cells was assessed by double-labeling immunohistochemistry. Neither Tbr2 nor Tbr2-GFP colocalized with the glial marker $\mathrm{S} 100 \beta$ (Fig.

Figure 2. Tbr2-GFP does not colocalize with glial markers, but short-term lineage tracing reveals colocalization with neuronal markers. Single-channel images are presented in gray scale. Orthogonal views are separated by white lines in each panel. A-C, Tbr2-GFP (arrow) did not clearly colocalize with GFAP (arrowhead), an astrocyte marker expressed in the processes but not cell bodies of type- 1 progenitors as well as astrocytes in the GCL. D-F, Tbr2-GFP (arrow) did not colocalize with the glial marker $\$ 100 \beta$ (arrowhead). G-I, Similar to Tbr2 protein expression, a small proportion of Tbr2-GFP+ cells colocalized with Sox2, an early IPC marker (arrowheads). $J-L$, Tbr2-GFP colocalized with a significant proportion of $D C X+$ cells (arrowhead). $M-0$, Similarly, coexpression of NeuroD, an immature granule neuron marker, was apparent in many Tbr2-GFP + cells (arrowheads). $\boldsymbol{P}-\boldsymbol{R}$, Many Tbr2GFP+ cells colocalized with calretinin (arrow, arrowhead), a marker of immature neurons in the DG. $\boldsymbol{S}-\boldsymbol{U}$, Some Tbr2GFP + cells colocalized with NeuN, which is expressed in all neuronal nuclei. Generally, Tbr2-GFP+/NeuN + cells expressed GFP more weakly (arrow) than Tbr2-GFP $+/ \mathrm{NeuN}-$ cells (arrowhead), suggesting that Tbr2-GFP expression is downregulated as postmitotic granule cells mature. Scale bar, $10 \mu \mathrm{m}$. 

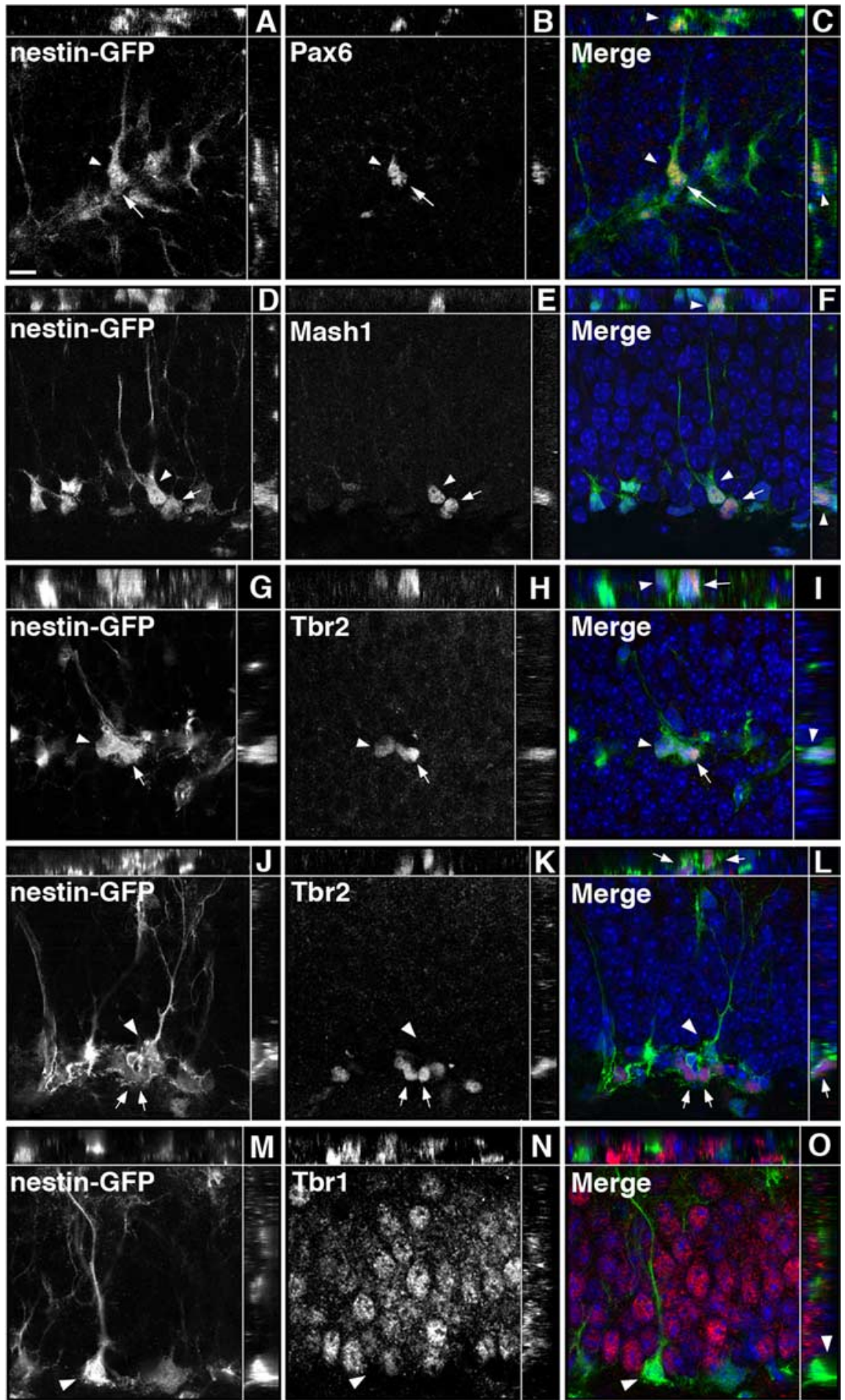

Figure 3. Sequential expression of TFs in nestin-GFP + progenitors. Single-channel images are presented in grayscale. $0 \mathrm{r}$ thogonal views are separated by the white lines in each panel. $\boldsymbol{A}-\boldsymbol{C}$, Pax6 was expressed in nestin-GFP + cells with a clearly visible radial process typical of type-1 cells (arrowhead) and in some adjacent nestin-GFP + type-2 cells (arrow). D-F, Mash1 was expressed in type-1 cells (arrowhead) and in some type-2 nestin-GFP + cells (arrow). G-I, Rarely, Tbr2 was weakly expressed in type-1 progenitors (arrowhead) but was more strongly expressed in adjacent nestin-GFP + cells with type-2 cell morphology (arrow). $J-L$,

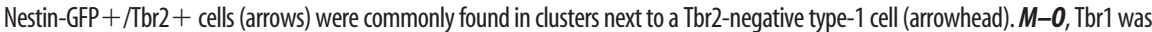
expressed in granule cells but did not colocalize with nestin-GFP+ progenitors (arrowhead). Scale bar, $10 \mu \mathrm{m}$.

$2 D-F)$ (data not shown). Clear colocalization of Tbr2 or Tbr2GFP with GFAP, a marker of type- 1 progenitors and astrocytes in the GCL, was difficult to assess because of the abundance and unclear cellular origin of GFAP+ processes in the GCL (Figs. 1 I,
$2 A-C)$. In some cases, Tbr2+ cells were surrounded by GFAP + processes, but it was impossible to determine whether these processes originated from the Tbr2+ cells themselves or from neighboring GFAP + cells (Fig. 1I). Therefore, we turned to nestin-GFP transgenic mice in which nestin-GFP is expressed in and reveals the morphology of subpopulations of both type- 1 and type- 2 progenitors (Filippov et al., 2003; Mignone et al., 2004) to more directly determine which progenitor populations express Tbr2. In total, $95.09 \pm 1.21 \%$ of Tbr $2+$ cells colabeled with nestin-GFP. Tbr2 + cells represented a smaller proportion of nestin-GFP + cells, accounting for only $30.98 \pm 0.44 \%$ of the total nestin-GFP+ population. When the morphology of cells colabeled with nestinGFP and Tbr2 was examined, only $3.24 \pm$ $0.39 \%$ of Tbr $2+$ cells were found to exhibit typical type-1 progenitor morphology, with a prominent radial process extending into the GCL (Fig. 3G-I). Tbr2 expression was weak in type-1 progenitors, and these cells appeared to be dividing to produce clusters of nestin-GFP+ cells with stronger Tbr2 expression (Fig. $3 G-I)$. Tbr2 + cells coexpressing nestinGFP were more typically found in clusters in the SGZ and were often noted to be in close association with a Tbr2-negative type-1 nestin-GFP + cell (Fig. $3 J-L$ ). Of all the nestin-GFP+, Tbr2+ double-labeled cells examined, $96.76 \pm 0.39 \%$ had morphology consistent with type- 2 progenitors, suggesting that Tbr2 expression is primarily restricted to IPCs.

Consistent with increasing expression of Tbr2 in the IPC component of SGZ progenitors, colabeling with Sox2, a TF expressed in many type- 1 and type- 2 (mainly type-2a) cells in the SGZ (Kronenberg et al., 2003; Ferri et al., 2004), showed that $34.5 \pm 5.9 \%$ of Tbr $2+$ cells were Sox $2+$, including some double-labeled mitotic figures (Fig. $4 A-C$ ). Tbr2 + cells represented a small proportion of the total Sox $2+$ population, accounting for only $17.39 \pm 3.15 \%$ of all Sox $2+$ cells (Fig. $4 S$ ). Pax6, also previously documented in type- 1 and type-2a cells (Maekawa et al., 2005; Nacher et al., 2005), colocalized with $35.7 \pm 1.7 \%$ of Tbr $2+$ cells, supporting expression of Tbr2 in early stage IPCs (Fig. $4 D-F)$. Similar to the results documented for Sox 2 , Tbr2 + cells accounted for only $17.92 \pm 1.07 \%$ of total Pax6 + cells (Fig. $4 S$ ). Additionally, Ngn2, likewise recently documented in type-2a SGZ progenitors (Ozen et al., 2007), colocalized with a subset of Tbr2+ cells (Fig. $4 J-L$ ).

DCX and polysialylated neural cell adhesion molecule (PSANCAM) were used to determine whether Tbr2 colocalizes with 

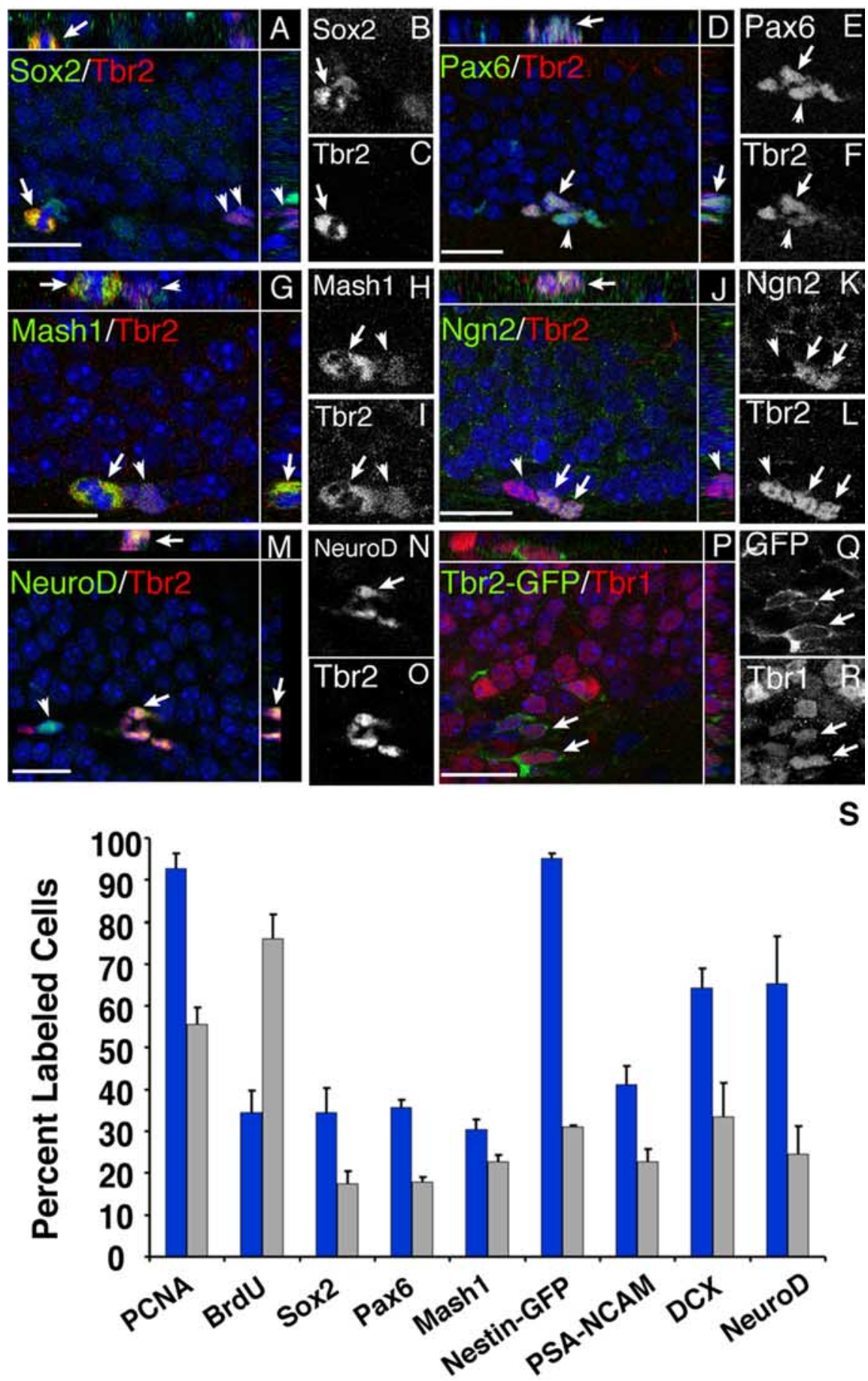

Double labeled (Marker+, Tbr2+) $\div$ Total Tbr2+ Cells

$\square$ Double labeled (Marker+, Tbr2+) $\div$ Total Marker+ Cells

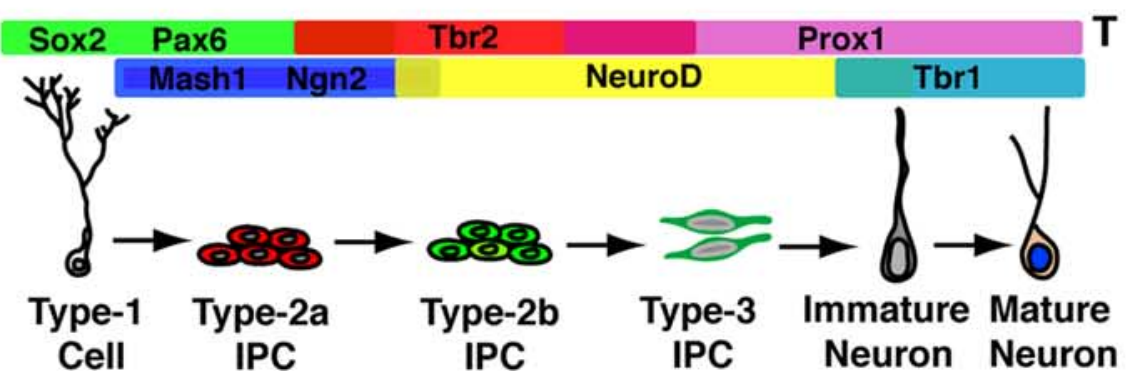

markers of progenitors committed to a neuronal lineage. The majority of Tbr2+ cells colabeled with DCX $(64.4 \pm 4.7 \%)$ (Fig. 4S). In general, these cells had low DCX expression, with either no processes or short, tangentially oriented processes, typical of type- 2 cells (Fig. $1 \mathrm{~K}$ ). PSANCAM colabeling was observed in $41.2 \pm$ $4.4 \%$ of Tbr $2+$ cells in the SGZ. These cells exhibited weak PSA-NCAM staining with small or absent processes similar to the pattern observed for DCX (Fig. 1J,K). Tbr $2+$ cells accounted for relatively small proportions of the DCX and PSA-NCAMpositive populations ( $\sim 33$ and $23 \%$, respectively) (Fig. 4S), suggesting that Tbr2 is progressively downregulated as cells become committed to the neuronal lineage and then exit the mitotic cycle. Consistent with this idea, Tbr2 did not colocalize with calretinin, a marker of immature granule cells (Fig. $1 \mathrm{~L}$ ). Similarly, Tbr2 did not colocalize with calbindin or NeuN (neuronal-specific nuclear protein), both of which are expressed in granule neurons (Fig. $1 M, N$ ).

To conclusively determine whether Tbr $2+$ cells give rise to a neuronal lineage, Tbr2-GFP transgenic mice were used (Fig. $1 A-C)$. The overlap between Tbr2 and Tbr2-GFP was first quantified, and it was found that although nearly all Tbr2 + cells expressed Tbr2-GFP $(92.53 \pm 0.33 \%)$, only $30.39 \pm 2.26 \%$ of Tbr 2 -GFP + cells were colabeled with Tbr2. These results suggested

Figure 4. Tbr2 is part of a TF cascade in the adult SGZ. Merged images are shown with orthogonal views separated by white lines in each panel. Single-channel images of double-labeled cells are shown in grayscale. $\boldsymbol{A}-\boldsymbol{C}$, Tbr2 colocalized with some Sox2 + cells in the SGZ, including doublelabeled mitotic figures (arrow). Clusters of Sox $2-/ \mathrm{Tbr} 2+$ cells were also apparent (arrowheads). D-F, Pax6+/Tbr2+ cell clusters were observed in the $S G Z$, with individual cells expressing varying levels of each TF (arrowhead). G-I, Mash1+ cells were often clustered with Tbr2+ cells, but strong coexpression occurred in only a small subset of labeled cells. Rarely, Mash1+/Tbr2 + mitotic figures were found (arrow) near strongly Tbr2 + cells that weakly expressed Mash1 (arrowhead). J-L, Clusters of Ngn2+/Tbr2 + cells (arrows) adjacent to Tbr2 $+/ \mathrm{Ngn} 2-$ cells (arrowhead) were observed. $\mathbf{M}-\mathbf{0}$, Neuro $D+/ \mathrm{Tbr} 2+$ cells were found frequently in clusters (arrow), but NeuroD expression was more widespread than Tbr2 expression, and single-labeled cells were common (arrowhead). $\boldsymbol{P}-\boldsymbol{R}$, Tbr1 was expressed in postmitotic granule cells, including some Tbr2-GFP + cells (arrows). S, Quantification of phenotypes of Tbr2-positive cells in the SGZ. Blue bars represent the fraction of $\mathrm{Tbr} 2+/$ marker + cells divided by total $\mathrm{Tbr} 2+$ cells. Gray bars represent the fraction of $\mathrm{Tbr} 2+1$ marker + cells divided by total marker + cells. Each marker is indicated on the $x$-axis. Error bars represent the mean \pm SEM for each phenotype. $\boldsymbol{T}$, Schematic diagram of TF expression in the DG. Scale bars, $20 \mu \mathrm{m}$. 
that Tbr2-GFP expression persisted longer than native Tbr2 protein expression, thus allowing for short-term lineage tracing to be conducted using Tbr2-GFP with double-labeling immunohistochemistry. Colocalization with Sox 2 indicated that, similar to Tbr2 expression, Tbr2-GFP was expressed early in the SGZ progenitor lineage (Fig. 2G-I). Persistent Tbr2-GFP expression revealed colocalization with several neuronal lineage markers, including DCX (Fig. $2 J-L$ ), calretinin (Fig. $2 P-R$ ), NeuN (Fig. $2 S-U$ ), and the granule cell markers Tbr1 (Fig. $4 P-R$ ) and Prox1 (data not shown). Quantification of Tbr2-GFP coexpression with NeuroD, a marker of newly generated granule cells (Pleasure et al., 2000; Schwab et al., 2000; Seki, 2002; Seri et al., 2004), indicated that $88.85 \pm 2.62 \%$ of Tbr2-GFP + cells coexpressed NeuroD, and that Tbr2-GFP + cells accounted for more than half of the population of NeuroD + neuroblasts $(58.64 \pm$ $8.95 \%)$. Together, these results strongly suggest that Tbr2+ cells ultimately give rise to new neurons in the adult GCL.

\section{Tbr2 is part of a TF cascade in the SGZ}

To examine whether TF cascades active during embryonic neurogenesis are recapitulated in the adult DG, a series of doublelabeling immunohistochemistry experiments was conducted. Pax6 expression was observed in many nestin-GFP + cells exhibiting typical type-1 cell morphology. In some cases, these cells appeared to be dividing to produce Pax6 + cells with morphology typical of type-2 progenitors (Fig. $3 A-C$ ). Colabeling with Tbr2 and Pax6 showed clusters of cells with double-labeled Tbr2+/ Pax6 + cells and single-labeled Pax6 + or Tbr2 + cells (Fig. 4D$F)$, supporting reports that Pax6 expression persists transiently into early type-2 cells (Maekawa et al., 2005; Nacher et al., 2005). Tbr2 + cells were frequently nestin-GFP + and had morphology consistent with type-2 progenitors (Fig. $3 G-L$ ). Nestin-GFP+/ Pax6+/Tbr2 + cells with morphology typical of type- 1 and type- 2 cells were also observed (supplemental Fig. 1, available at www.jneurosci.org as supplemental material). A majority of Tbr $2+$ cells $(65.3 \pm 11.4 \%)$ colocalized with NeuroD, and these cells were often apparent in clusters in the SGZ (Fig. 4M-O). However, NeuroD expression was more widespread in the GCL with only $24.5 \pm 6.7 \%$ of NeuroD + cells coexpressing Tbr2 (Fig. $4 S$ ), confirming that NeuroD expression persists into postmitotic neuroblasts (Pleasure et al., 2000; Schwab et al., 2000; Seki, 2002; Seri et al., 2004). Tbr1 expression was observed only in postmitotic granule cells and was not detected in progenitor cells, because Tbr 1 never colocalized with nestin-GFP (Fig. 3M-O). These results suggest that sequential expression of $\operatorname{Pax} 6 \rightarrow$ Tbr $2 \rightarrow$ Tbr 1 occurs during glutamatergic neurogenesis in the adult DG (Fig. 4T), as in the developing neocortex (Englund et al., 2005).

Several other TFs were examined to determine their relationship with Tbr2+ cells in the SGZ (Fig. 4S,T). Ngn2 was shown previously to be expressed by type- 1 and type-2a progenitors in the SGZ (Ozen et al., 2007). We found very few Ngn2 + cells in SGZ, as others have noted (Ozen et al., 2007), making quantitative estimates difficult to determine; however, Ngn2 was observed to colocalize with a subset of Tbr2+ cells (Fig. $4 J-L$ ). Previous studies demonstrated Mash1 expression in clustered cells in the SGZ, some of which expressed GFAP (Pleasure et al., 2000; Kim et al., 2007; Seki et al., 2007). Similarly, we found that Mash1 was expressed in some nestin-GFP+ type-1 cells and in a subset of nestin-GFP + cells with type- 2 cell morphology (Fig. $3 D-F)$. Mash $1+$ cells accounted for a subset of Tbr2+ cells (30.41 $\pm 2.40 \%$ ) (Fig. $4 S$ ); double-labeled cells included mitotic figures, indicating overlap of Mash 1 and Tbr2 expression within proliferating progenitors (Fig. 4G-I). Triple labeling with Mash1, Tbr2, and nestin-GFP showed Mash1+ type-1 cells adja- cent to clusters of nestin-GFP+/Tbr2 + type-2 cells (supplemental Fig. 2, available at www.jneurosci.org as supplemental material), suggesting that Mash1 expression may precede Tbr2 expression in SGZ progenitors. Consistent with this idea, Tbr2+ cells accounted for only $22.68 \pm 1.60 \%$ of all Mash $1+$ cells in the SGZ (Fig. 4S). These findings expand the commonality of sequential TF expression between developing neocortex and adult hippocampus, to at least include Pax $6 \rightarrow \mathrm{Ngn} 2 \rightarrow$ Tbr $2 \rightarrow$ NeuroD $\rightarrow$ Tbr1 (Fig. 4T). Additional TFs, including high-level Mash1 and Prox1, appear to be attached to this core TF cascade as part of a DG-specific program that is not activated in embryonic neocortex. [However, low levels of Mash1 may be expressed in many embryonic neocortical progenitors (Britz et al., 2006)].

\section{BrdU pulse chase confirms expression of Tbr2 in type-2 progenitors}

The time course of appearance of Tbr2 + cells in different progenitor subpopulations was examined using a BrdU pulse chase time series experiment (Kronenberg et al., 2003). To examine the expression of Tbr2 in early IPC progenitor stages (type-2a and type-2b progenitors), colabeling with Sox 2 was used (Steiner et al., 2006). Two hours after administration of BrdU, $>90 \%$ of BrdU + cells coexpressed either Tbr2 or Sox2, and a majority of the BrdU+ cells expressed both of these TFs $(58.67 \pm 2.64 \%)$ (Fig. 5A). Very few proliferating cells expressed only Tbr2 at this time point $(7.56 \pm 1.23 \%)$, indicating that rapidly proliferating population consisted primarily of type-2a and type-2b Sox $2+1$ Tbr2+ progenitors. Sox $2+/$ BrdU + cells accounted for $23.4 \pm$ $3.1 \%$ of the BrdU-labeled cells at this time point, consistent with the predominance of early IPCs (type-2a cells) $2 \mathrm{~h}$ after BrdU administration (Kronenberg et al., 2003; Steiner et al., 2006). The proportion of BrdU + cells labeled with Tbr2 and not Sox 2 correspondingly increased $24 \mathrm{~h}$ after BrdU administration (36.35 \pm $1.95 \%)$, whereas the proportion of BrdU+ cells expressing only Sox 2 decreased $(9.92 \pm 0.49 \%$ ) (Fig. $5 A$ ), likely reflecting a shift toward increased numbers of type- $2 \mathrm{~b}$ and type- 3 cells $24 \mathrm{~h}$ after BrdU administration, as described previously (Kronenberg et al., 2003). At both the 2 and 24 h survival times, very few BrdU+ cells were unidentifiable (expressing neither Sox2 nor Tbr2), indicating that most of the proliferating population at these survival times consisted of the rapidly dividing type- 2 and type- 3 cell populations, supporting previous studies of SGZ progenitor development (Kronenberg et al., 2003). Three days after BrdU administration, the majority of BrdU + cells did not express Tbr2 or Sox2, reflecting a shift toward later IPC stages (type-3 cells) and increased production of postmitotic neuroblasts. This trend continued at the $7 \mathrm{~d}$ survival time point, by which time very few BrdU + cells expressed Tbr2 or Sox 2 (Fig. $5 A$ ).

To examine the progression of Tbr + cells through later IPC stages (type- $2 \mathrm{~b}$ and type- 3 cells), time series experiments were performed with BrdU, DCX, and Tbr2 triple labeling. DCX expression begins in type-2b cells and persists into postmitotic immature neurons (Kronenberg et al., 2003; Kempermann et al., 2004 b). Two hours after BrdU injection, $>75 \%$ of BrdU+ cells were positive for either Tbr2 $(57.17 \pm 1.1 \%)$ or both Tbr2 and DCX $(21.6 \pm 0.67 \%)$ again reflecting the predominance of type-2a (Tbr2+) and type-2b (Tbr2+/DCX +$)$ cells at this stage. Significantly, no Tbr2-/DCX $+/$ BrdU + cells were observed $2 \mathrm{~h}$ after BrdU injection, suggesting that all of the actively dividing DCX + progenitors at this stage strictly express Tbr2. By $24 \mathrm{~h}$ after BrdU injection, increased numbers of BrdU+/DCX $+/$ Tbr2 + triple-labeled cells were apparent, and the number of BrdU+ cells labeled only with Tbr2 (and not DCX) decreased corre- 

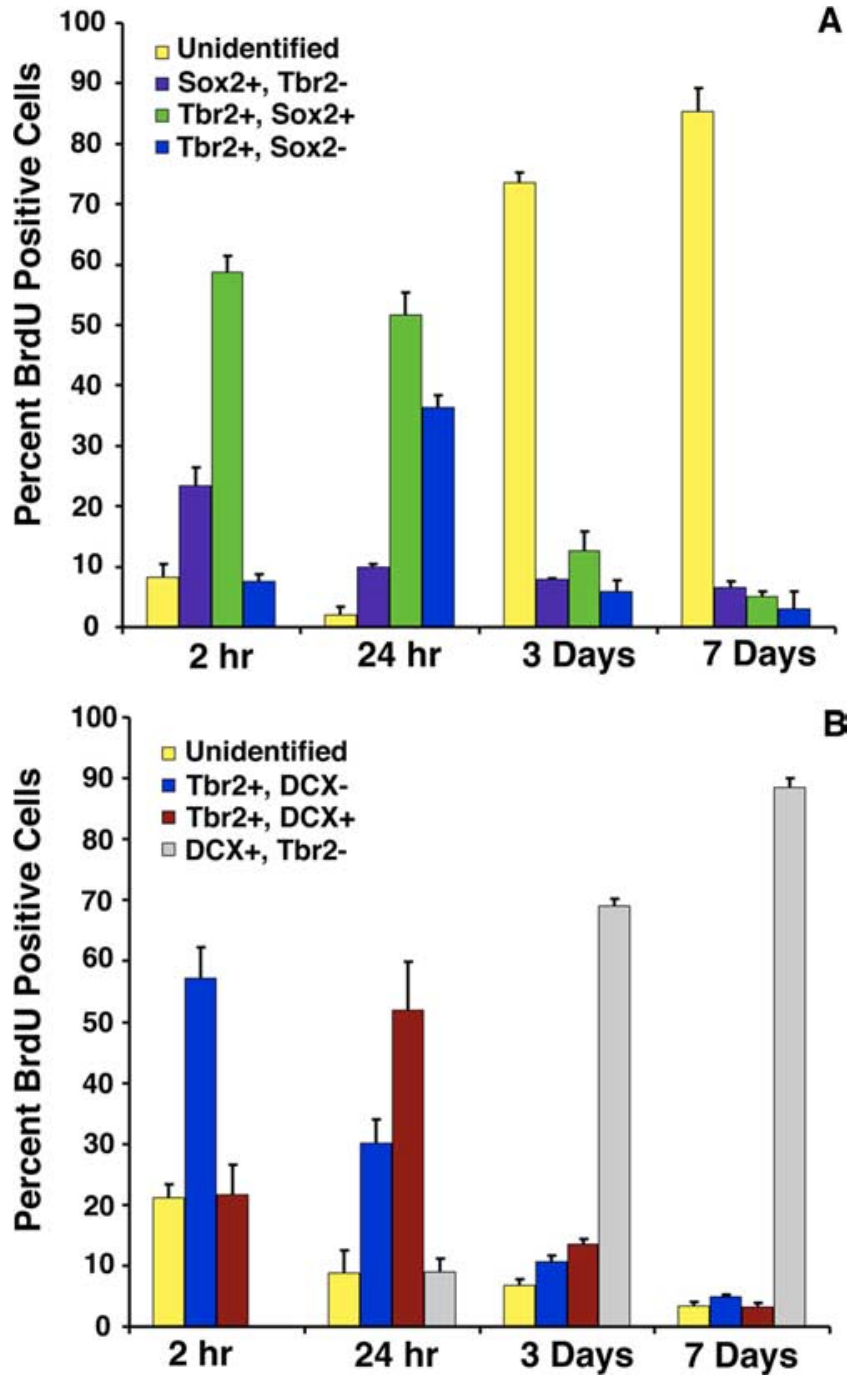

Figure 5. BrdU pulse chase time series experiments. Animals were collected at survival times $2 \mathrm{~h}, 24 \mathrm{~h}, 3 \mathrm{~d}$, and $7 \mathrm{~d}$ after administration of a single pulse of BrdU. $A$, Triple labeling with $\mathrm{BrdU} / \mathrm{Sox2} / \mathrm{Tbr} 2$ revealed the time course of appearance of Tbr2 in early stage IPCS (type-2a and type-2b progenitors). At early time points $(2 \mathrm{~h}, 24 \mathrm{~h})$, most BrdU + cells coexpressed Tbr2 (blue bars), Sox2 (purple bars), or both Tbr2 and Sox2 (green bars). Cells labeled with only BrdU (unidentified, yellow bars) were rare at 2 and $24 \mathrm{~h}$ but increased in proportion at 3 and $7 \mathrm{~d}$ after BrdU administration. Correspondingly, Tbr2+, Sox2+, and Tbr2+/Sox2+ labeled cells decreased at the 3 and $7 \mathrm{~d}$ survival times. $B$, Triple labeling with BrdU/DCX/Tbr2 showed the time course of appearance of Tbr2 in later-stage IPCs (type-3 cells). At 2 and $24 \mathrm{~h}$ after BrdU administration, most BrdU + cells expressed Tbr2 (blue bars) or both Tbr2 and DCX (red bars). At 3 and $7 \mathrm{~d}$ after BrdU injection, the proportions of BrdU $+/ \mathrm{Tbr} 2+$ cells and BrdU +/DCX +/Tbr2 + cells declined, and most labeled cells were BrdU +/DCX + (gray bars), consistent with lineage progression to postmitotic neurons at later time points. Error bars represent the mean \pm SEM for each cell type in $\boldsymbol{A}$ and $\boldsymbol{B}$.

spondingly (Fig. $5 B$ ), reflecting the shift in the progenitor population toward greater numbers of type- $2 \mathrm{~b}$ and type- 3 progenitors at this stage (Kronenberg et al., 2003). This stage also marked the first appearance of DCX $+/$ BrdU + cells that did not express Tbr2 (9.05 $\pm 2.13 \%$ of all BrdU + cells) (i.e., postmitotic neuroblasts). By $3 \mathrm{~d}$ after BrdU injection, DCX $+/$ Tbr2- cells represented the majority of all BrdU-labeled cells (68.99 $\pm 3.85 \%)$, whereas BrdU $+/$ Tbr $2+/ \mathrm{DCX}-$ and BrdU $+/ \mathrm{DCX}+/ \mathrm{Tbr} 2+$ cells together accounted for $<25 \%$ of all BrdU+ cells (Fig. $5 B$ ), indicative of decreased numbers of early stage IPCs by this survival time (Kronenberg et al., 2003). This trend continued at $7 \mathrm{~d}$ after BrdU administration, by which point BrdU $+/ \mathrm{DCX}+/ \mathrm{Tbr} 2-$ cells ac- counted for $88.56 \pm 7.94 \%$ of all BrdU + cells, and BrdU + cells labeled only with Tbr2 or Tbr2/DCX accounted for $<10 \%$ of the BrdU-labeled population. These results are consistent with previous reports demonstrating declining numbers of type- 2 and type- 3 at $7 \mathrm{~d}$ after BrdU administration, by which time BrdUlabeled cells have begun to differentiate into postmitotic neuroblasts (Kronenberg et al., 2003). Together, these studies suggest that Tbr2 is predominantly expressed in early IPCs (type-2), with expression rapidly declining as newly generated cells differentiate into granule neurons.

\section{Running upregulates Tbr2 + cells in the SGZ}

The effect of a known neurogenic stimulus on Tbr2 + cells in the SGZ was analyzed in mice allowed $10 \mathrm{~d}$ of voluntary access to a running wheel (RUN mice), which has been shown previously to increase neurogenesis 1.5-fold to twofold (van Praag et al., 1999; Kronenberg et al., 2003). Tbr2 + cells were markedly stimulated in RUN mice ( $3150.5 \pm 337.4$ cells/DG), increasing by $\sim 2.5$-fold compared with CTR mice $(1282.5 \pm 245.5$ cells/DG; $F=26.50$; $p=0.001$ ) (Fig. 6A-E). The number of Tbr2 + cells in RUN $28 \mathrm{~d}$ mice $(903 \pm 30.3$ cells/DG), which were denied running wheel access for 4 weeks after the initial $10 \mathrm{~d}$ period with running wheel access, was significantly less than RUN mice $(p<0.001)$ and did not differ significantly from age-matched controls (CTR 14 weeks, $822 \pm 71.7$ cells/DG). These results indicate that the increase of Tbr2 + cells in RUN mice was transient and directly related to the neurogenic stimulus (Fig. 6E). The decline in Tbr2+ cells in RUN 28 d mice may also be partially attributable to an age-related decrease in proliferation (Kronenberg et al., 2006). Tbr $2+/ \mathrm{BrdU}+$ double-labeled cells likewise increased in RUN mice ( $1185 \pm 130.6$ cells/DG), more than doubling relative to CTR mice ( $570 \pm 76.8$ cells/DG; $t=4.058$; $p<0.01$ ), confirming that the Tbr2 + cells in RUN mice were proliferating progenitors. Tbr2 +/BrdU + cells were not observed in RUN 28 d mice, suggesting that surviving BrdU+ cells differentiated and ceased to express Tbr2 by this time.

\section{Running increases the size of Tbr $2+$ cell clusters}

Small clusters of Tbr2 + cells were observed frequently in the SGZ of both RUN (Fig. 6B,D) and CTR (Fig. 6A,C) mice, but the clusters seemed to be somewhat larger in RUN mice. To determine whether running affected cluster size (the number of cells per cluster), Tbr + cell clusters were enumerated in both groups. Mean cluster size was significantly doubled in RUN mice (5.22 \pm 0.17 cells) compared with CTR mice ( $2.46 \pm 0.09$ cells; $t=12.08$; $p<0.001)$. The number of clusters per DG did not differ significantly between groups $(t=2.08 ; p=0.08)$; however, there was a trend toward more clusters per DG in RUN mice (RUN, $146 \pm 27$ clusters/DG; CTR, $86 \pm 10$ clusters/DG). In CTR mice, most Tbr2 + cells were present as single cells or pairs of cells. The frequency of clusters larger than four cells was low in CTR mice, and clusters larger than eight cells were very rare (Fig. $6 \mathrm{~F}$ ). In contrast, the frequency of clusters of one to two cells was lower in RUN mice. Clusters of 4-10 Tbr2+ cells were common, and large clusters between 12 and 18 cells in size were also observed, albeit at a low frequency. Rarely, clusters of up to 20-24 Tbr2+ cells were observed, consistent with a notable shift to larger cluster sizes in RUN mice (Fig. 6F).

Antimitotic drug treatment decreases Tbr2+ cells in the SGZ To determine whether Tbr2+ cells correspond to the major population of actively dividing neurogenic progenitors (Seri et al., 2004), mice were treated with antimitotic drugs to ablate rapidly 

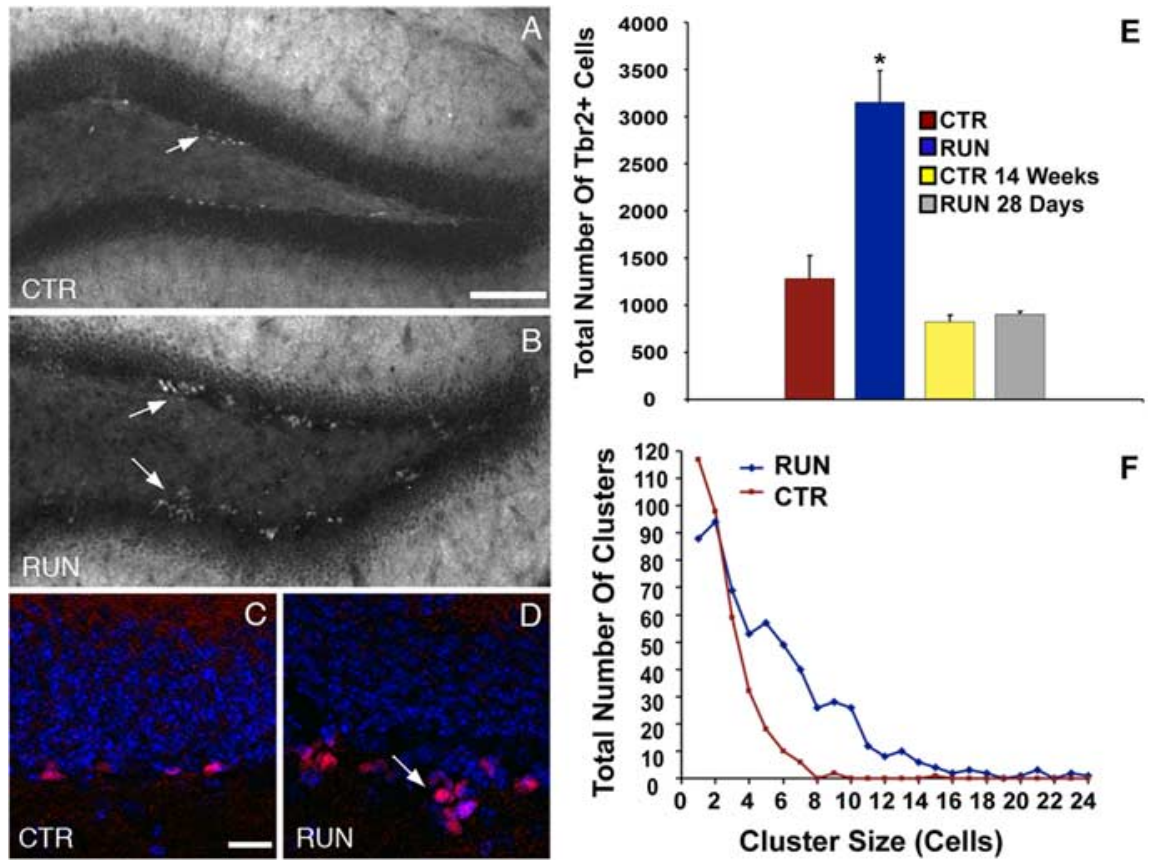

Figure 6. Running increases Tbr2 + cells in the DG. CTR mice $(\boldsymbol{A}, \boldsymbol{C})$ exhibited visibly lower numbers of Tbr2 + cells than RUN mice $(\boldsymbol{B}, \boldsymbol{D})$. Large clusters of Tbr2 + cells extending into the hilus were apparent in RUN mice ( $\boldsymbol{B}, \boldsymbol{D}$, arrows). $\boldsymbol{E}$, Total Tbr2 + cells were increased by 2.5 -fold in RUN mice $\left(^{*} p=0.001\right.$ ) but returned to control levels (CTR, CTR 14 weeks) $28 \mathrm{~d}$ after running (RUN $28 \mathrm{~d}) . \boldsymbol{F}$, RUN mice had an increased frequency of large clusters of Tbr2 + cell. In CTR mice, most Tbr2 + cells were present as single cells or doublets. In RUN mice, clusters of more than four cells were common, and very large clusters of $>20$ Tbr $2+$ cells were documented. Scale bars: $\boldsymbol{A}, \boldsymbol{B}, 100 \mu \mathrm{m} ; \boldsymbol{C}, \boldsymbol{D}, 20 \mu \mathrm{m}$. Bar graphs show the mean \pm SEM for each group.

dividing cells in the SGZ, and Tbr2+ and Tbr2+/BrdU+ cells were then counted at specific intervals after the withdrawal of drug treatment. Cell counts from sham-operated and unoperated control animals did not differ significantly and were pooled into a single control group. ANOVA results for Tbr2+ cell counts revealed highly significant differences between control and antimitotic drug-treated groups $(F=35.74 ; p<0.001)$ (Fig. $7 A)$. At $0 \mathrm{~d}$ posttreatment, Tbr $2+$ cells were reduced to $<10 \%$ of control values $(p<0.001)$, indicating a near ablation of Tbr $2+$ cells. Two days after treatment, the number of Tbr2+ cells was $63 \%$ lower than controls $(p<0.001)$. By $5 \mathrm{~d}$ posttreatment, Tbr2+ cells returned to control values. However, at $15 \mathrm{~d}$ posttreatment, Tbr + cells increased to $69 \%$ above controls $(p<0.001)$. This rebound spike in Tbr2+ cells was transient and fell back to control levels by $30 \mathrm{~d}$ posttreatment (Fig. $7 A$ ).

Counts of proliferating, Tbr $2+/ \mathrm{BrdU}+$ cells followed the same pattern. ANOVA results again indicated a highly significant difference between groups $(F=16.64 ; p<0.001)$ (Fig. $7 B$ ). Tbr $2+/$ BrdU + cells were nearly absent at $0 \mathrm{~d}$ posttreatment, reaching only $4 \%$ of the control value $(p<0.001)$, and remained low at $2 \mathrm{~d}$ posttreatment ( $57 \%$ of controls; $p<0.05)$. At $5 \mathrm{~d}$ posttreatment, Tbr $2+/ \mathrm{BrdU}+$ cells did not differ from controls; however, a significant increase in Tbr $2+/ \mathrm{BrdU}+$ cells above control levels was observed at $15 \mathrm{~d}$ posttreatment $(p=0.005)$ and was again followed by a return to control levels at $30 \mathrm{~d}$ posttreatment (Fig. $7 B$ ). When represented as a percentage of total BrdU+ cells, Tbr $2+/ \mathrm{BrdU}+$ cells exhibit a similar pattern of increase from day 0 to control levels at day 5, accounting for only $4.8 \pm$ $2.1 \%$ of BrdU + cells at day $0,21.6 \pm 3.9 \%$ at day 2 , and $41.4 \pm$ $1.4 \%$ at day 5 (Fig. 7 C). Tbr $2+/$ BrdU + cells represented $49.6 \pm$ $6.8 \%$ of BrdU + cells at day 15 and $49.0 \pm 2.3 \%$ at day 30 , both of which were approximately equivalent to controls $(44.6 \pm 1.7 \%)$.

\section{Discussion}

The present study shows that Tbr2, a TF specifically expressed in IPCs of the embryonic cortex (Englund et al., 2005), is similarly expressed in type-2 IPCs, with expression continuing into type-3 IPCs in the adult DG. Our results show that Tbr2 + cells in the SGZ exhibit morphologies typical of type- 2 and type- 3 progenitors and express markers of neuronal lineage restricted progenitors (Kempermann et al., 2004b; Steiner et al., 2006). Furthermore, studies of nestin-GFP mice revealed rare expression of Tbr2 in a small number of type- 1 progenitors. Typically, Tbr2+ cells formed nestin-GFP + clusters in close proximity to type- 1 progenitors. Colocalization with Pax6, Sox2, and Ngn2, all previously shown to be expressed in type-1 and type-2a progenitors (Kronenberg et al., 2003; Nacher et al., 2005; Ozen et al., 2007), suggests that Tbr2 is upregulated early in the transition between type-1 progenitors and IPCs. Our data demonstrating the proliferation of Tbr2+ cells supports the morphological identification of Tbr $2+$ cells as mainly type- 2 cells or IPCs. Previous studies have shown that type-2 cells proliferate rapidly and are readily labeled by acutely administered BrdU (Seri et al., 2001; Filippov et al., 2003; Kronenberg et al., 2003; Seri et al., 2004; Steiner et al., 2006). We found that a significant proportion of Tbr $2+$ cells (34\%) are labeled by a single BrdU pulse, and that $>90 \%$ of Tbr $2+$ cells express PCNA, a marker of cycling cells. Results from BrdU pulse chase time series experiments likewise supported the identification of Tbr $2+$ cells as rapidly cycling IPCs. These experiments suggested that the majority of proliferating cells 2 and $24 \mathrm{~h}$ after BrdU administration express Tbr2, with Tbr2 expression declining in the BrdU+ population at later survival time points ( 3 and $7 \mathrm{~d}$ ). These results closely parallel previous studies showing that most BrdU + cells can be identified as type- $2 \mathrm{a}$, type- $2 \mathrm{~b}$, or type- 3 progenitors at 2 and $24 \mathrm{~h}$ after BrdU injection, with these IPC subpopulations declining in favor of postmitotic neurons at later survival times (Kronenberg et al., 2003).

Regarding cell fates, our results suggest that Tbr2+ progenitors are committed to a neuronal but not glial lineage, because neither Tbr2-protein nor Tbr2-GFP colocalized with glial markers. The presence of Tbr2-GFP+/Tbr1 + cells indicated that Tbr $2+$ progenitors produce new granule neurons. Our estimates of total Tbr $2+$ cell number in control animals $(\sim 1200$ cells $)$ closely matched previous estimates of the size of the proliferative population in C57BL/6 mice ( $\sim 1600$ cells) (Hayes and Nowakowski, 2002). Together, our results suggest that Tbr2 is a specific marker of IPCs and support the use of Tbr2 expression as a measure of neurogenesis in the adult DG.

Rapidly cycling IPCs have been suggested previously as a target of neurogenic stimuli, including running (Kronenberg et al., 2003). Our data from RUN mice clearly show that Tbr2 + cells are upregulated in response to exercise. The increase in Tbr2 + cells shown here correlates well with previous studies showing a 1.5fold increase in BrdU + cells after running (van Praag et al., 1999; Kronenberg et al., 2003). Because our data indicate that Tbr2 


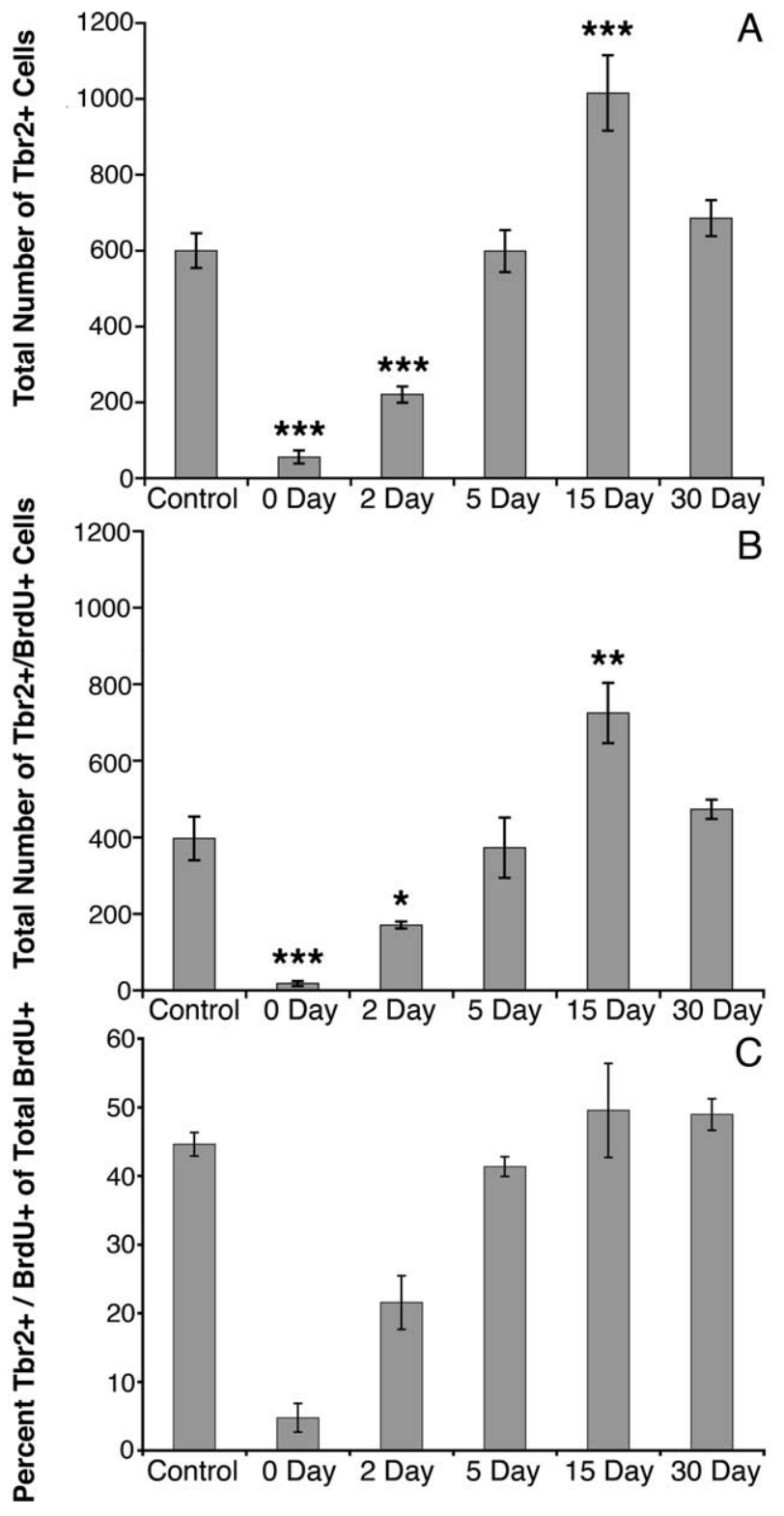

Figure 7. Antimitotic drug treatment decreases Tbr2 + cells in the DG. Animals were given antimitotic drugs for $7 \mathrm{~d}$ and examined $0,2,5,15$, and $30 \mathrm{~d}$ after treatment. $\boldsymbol{A}$, At 0 and $2 \mathrm{~d}$ posttreatment, Tbr2 + cells were significantly reduced compared with control. Tbr2 + cells reached control numbers by $5 \mathrm{~d}$ but surpassed controls at $15 \mathrm{~d}$ survival. By $30 \mathrm{~d}$ survival, Tbr $2+$ cells returned to control values. $\boldsymbol{B}$, Counts of $\mathrm{Tbr} 2+/ \mathrm{BrdU}+$ progenitor cells showed the same pattern as Tbr2 + cell counts at each survival time point. C, Tbr2 +/BrdU + cells represented a small fraction of total BrdU + cells at $0 \mathrm{~d}$ survival and increased thereafter. By $5 \mathrm{~d}$ survival, $\mathrm{Tbr} 2+/$ BrdU + cells reached control levels and represented a constant proportion of the total $\mathrm{BrdU}+$ cell population at subsequent survival times. Bars represent the mean $\pm \mathrm{SEM}$ for each group. ${ }^{*} p<0.05,{ }^{* *} p=0.005,{ }^{* * *} p<0.001$.

specifically labels IPCs, the present study supports previous evidence that type- 2 cells are regulated by neurogenic stimuli. These results suggest that Tbr2 may be used as a direct indicator of neurogenesis without the requirement of extra in vivo labeling techniques. It should also be noted that not all BrdU+ cells expressed Tbr2 in RUN mice. Because astrocyte proliferation is also increased with running (Steiner et al., 2004), DG progenitors are presumably heterogeneous with regards to lineage fates. Because Tbr2 expression was restricted to the neuronal lineage, its use in future studies as a marker of neurogenesis will provide enhanced specificity over BrdU alone.
In addition to increased Tbr2 + cells, cell cluster size was doubled in RUN mice. Previous reports showed that proliferating cells form clusters in the SGZ and suggested that clustering facilitates intercellular contacts or signals that promote neurogenesis (Seri et al., 2004; Seki et al., 2007). We observed fewer single Tbr2+ cells in RUN mice, suggesting increased clustering. Although total cluster number did not significantly increase in RUN mice, the frequency of large cell clusters and the average size of clusters were clearly increased. These large clusters may result from increased division of either type-1 progenitors or IPCs. Given that type- 1 cells divide at a slow rate, we speculate that the increase in mean Tbr2 + cluster size results from an increase in progenitor divisions at the IPC stage, perhaps because of increased probability of cell cycle re-entry. We further propose that Tbr2 + IPCs represent a major regulatory point in adult DG neurogenesis, similar to their suggested role in embryonic neocortical neurogenesis (Pontious et al., 2008).

The identification of Tbr2 + cells as IPCs is further supported by the results of our antimitotic treatment experiments. Previous reports have described return of type- 2 cells $2-5 \mathrm{~d}$ after discontinuing antimitotic treatment (Seri et al., 2001, 2004), essentially identical to our results. Unexpectedly, we observed a rebound increase in Tbr2 + cells $15 \mathrm{~d}$ after treatment, which may represent an attempt to restore normal neuron numbers after prolonged ablation. Others have noted increased BrdU+ cell density after antimitotic treatment but did not specify the cell types responsible for this increase (Seri et al., 2001). Importantly, Tbr2+ and Tbr2 +/BrdU + cells exhibited an identical time course of recovery after ablation, strongly supporting a link between Tbr2 expression and the proliferative response.

Our results suggest that Tbr2 is expressed as part of a TF cascade that closely resembles embryonic neocortical neurogenesis (Englund et al., 2005; Hevner, 2006). In both cases, the sequential expression of Pax $6 \rightarrow \mathrm{Ngn} 2 \rightarrow$ Tbr $2 \rightarrow$ NeuroD $\rightarrow$ Tbr 1 correlates with transition from primary to intermediate progenitor stages and ultimately to new glutamatergic neurons. Ngn2, which is directly regulated by Pax6 during cerebral cortical development (Heins et al., 2002; Scardigli et al., 2003) and may in turn regulate Tbr2 (Schuurmans et al., 2004) was coexpressed in some Tbr $2+$ cells in adult SGZ. This finding supported our conclusion that Ngn2 fits into the TF cascade between Pax6 and Tbr2, consistent with a recent report showing that Ngn2 is expressed in type- 1 and type-2a progenitors in the adult DG (Ozen et al., 2007). Mash1 also appears to be expressed upstream of Tbr2 in DG progenitors, although the role of Mash1 in cerebral cortex development is less certain. During development, Ngn1/2 represses Mash1 expression to regulate maturation of cortical progenitor cells (Britz et al., 2006). Others have shown Mash1 expression in GFAP + type-1 cells and some type-2 IPCs in adult SGZ (Kim et al., 2007; Seki et al., 2007), consistent with our results. Whereas the TF expression patterns described here are suggestive of a conserved TF program involved in glutamatergic neurogenesis, we have not established direct interactions between individual TFs. Nonetheless, our results strongly suggest that TF expression cascades, along with environmental stimuli, regulate neurogenesis in the adult DG.

In summary, we have shown that Tbr2 is a specific marker of type-2 IPCs in the adult DG. Moreover, Tbr2+ IPC numbers were directly correlated with induced changes in neurogenesis, suggesting that Tbr2 expression may be a useful measure of adult DG neurogenesis. As well, these studies show that Tbr2 is expressed as part of a TF cascade, which likely regulates the transi- 
tion from proliferating progenitor cells to differentiated glutamatergic neurons.

\section{References}

Arlotta P, Molyneaux B, Chen J, Inoue J, Kominami R, Macklis J (2005) Neuronal subtype-specific genes that control corticospinal motor neuron development in vivo. Neuron 45:207-221.

Britz O, Mattar P, Nguyen L, Langevin L, Zimmer C, Alam S, Guillemot F, Schuurmans C (2006) A role for proneural genes in the maturation of cortical progenitor cells. Cereb Cortex 16:i138-i151.

Emsley J, Mitchell B, Kempermann G, Macklis J (2005) Adult neurogenesis and repair of the adult CNS with neural progenitors, precursors, and stem cells. Prog Neurobiol 75:321-341.

Encinas J, Vaahtokari A, Enikolopov G (2006) Fluoxetine targets early progenitor cells in the adult brain. Proc Natl Acad Sci USA 103:8233-8238.

Englund C, Fink A, Lau C, Pham D, Daza R, Bulfone A, Kowalczyk T, Hevner R (2005) Pax6, Tbr2, and Tbr1 are expressed sequentially by radial glia, intermediate progenitor cells, and postmitotic neurons in developing neocortex. J Neurosci 25:247-251.

Ernst C, Olson AK, Pinel JPJ, Lam RW, Christie BR (2006) Antidepressant effects of exercise: evidence for an adult-neurogenesis hypothesis? J Psychiatry Neurosci 31:84-92.

Espósito M, Piatti V, Laplagne D, Morgenstern N, Ferrari C, Pitossi F, Schinder A (2005) Neuronal differentiation in the adult hippocampus recapitulates embryonic development. J Neurosci 25:10074-10086.

Ferri A, Cavallaro M, Braida D, Di Cristofano A, Canta A, Vezzani A, Ottolenghi S, Pandolfi P, Sala M, DeBiasi S, Nicolis S (2004) Sox2 deficiency causes neurodegeneration and impaired neurogenesis in the adult mouse brain. Development 131:3805-3819.

Filippov V, Kronenberg G, Pivneva T, Reuter K, Steiner B, Wang L, Yamaguchi M, Kettenmann H, Kempermann G (2003) Subpopulation of nestin-expressing progenitor cells in the adult murine hippocampus shows electrophysiological and morphological characteristics of astrocytes. Mol Cell Neurosci 23:373-382.

Gong S, Zheng C, Doughty M, Losos K, Didkovsky N, Schambra U, Nowak N, Joyner A, Leblanc G, Hatten M, Heintz N (2003) A gene expression atlas of the central nervous system based on bacterial artificial chromosomes. Nature 425:917-925.

Guillemot F (2007) Spatial and temporal specification of neural fates by transcription factor codes. Development 134:3771-3780.

Haubensak W, Attardo A, Denk W, Huttner W (2004) Neurons arise in the basal neuroepithelium of the early mammalian telencephalon: a major site of neurogenesis. Proc Natl Acad Sci USA 101:3196-3201.

Hayes N, Nowakowski R (2002) Dynamics of cell proliferation in the adult dentate gyrus of two inbred strains of mice. Brain Res Dev Brain Res 134:77-85.

Heins N, Malatesta P, Cecconi F, Nakafuku M, Tucker K, Hack M, Chapouton P, Barde Y, Götz M (2002) Glial cells generate neurons: the role of the transcription factor Pax6. Nat Neurosci 5:308-315.

Hevner RF (2006) From radial glia to pyramidal-projection neuron: transcription factor cascades in cerebral cortex development. Mol Neurobiol 33:33-50.

Hevner RF, Hodge RD, Daza RAM, Englund C (2006) Transcription factors in glutamatergic neurogenesis: conserved programs in neocortex, cerebellum, and adult hippocampus. Neurosci Res 55:223-233.

Jessberger S, Römer B, Babu H, Kempermann G (2005) Seizures induce proliferation and dispersion of doublecortin-positive hippocampal progenitor cells. Exp Neurol 196:342-351.

Kempermann G, Wiskott L, Gage F (2004a) Functional significance of adult neurogenesis. Curr Opin Neurobiol 14:186-191.

Kempermann G, Jessberger S, Steiner B, Kronenberg G (2004b) Milestones of neuronal development in the adult hippocampus. Trends Neurosci 27:447-452.

Kim EJ, Leung CT, Reed RR, Johnson JE (2007) In vivo analysis of Ascl1 defined progenitors reveals distinct developmental dynamics during adult neurogenesis and gliogenesis. J Neurosci 27:12764-12774.

Kronenberg G, Reuter K, Steiner B, Brandt M, Jessberger S, Yamaguchi M, Kempermann G (2003) Subpopulations of proliferating cells of the adult hippocampus respond differently to physiologic neurogenic stimuli. J Comp Neurol 467:455-463.

Kronenberg G, Bick-Sander A, Bunk E, Wolf C, Ehninger D, Kempermann G (2006) Physical exercise prevents age-related decline in precursor cell activity in the mouse dentate gyrus. Neurobiol Aging 27:1505-1513.
Maekawa M, Takashima N, Arai Y, Nomura T, Inokuchi K, Yuasa S, Osumi N (2005) Pax6 is required for production and maintenance of progenitor cells in postnatal hippocampal neurogenesis. Genes Cells 10:1001-1014.

Mignone J, Kukekov V, Chiang A, Steindler D, Enikolopov G (2004) Neural stem and progenitor cells in nestin-GFP transgenic mice. J Comp Neurol 469:311-324.

Miyata T, Kawaguchi A, Saito K, Kawano M, Muto T, Ogawa M (2004) Asymmetric production of surface-dividing and non-surface-dividing cortical progenitors. Development 131:3133-3145.

Nacher J, Varea E, Blasco-Ibañez J, Castillo-Gomez E, Crespo C, MartinezGuijarro F, McEwen B (2005) Expression of the transcription factor Pax 6 in the adult rat dentate gyrus. J Neurosci Res 81:753-761.

Noctor SC, Martínez-Cerdeño V, Ivic L, Kriegstein AR (2004) Cortical neurons arise in symmetric and asymmetric division zones and migrate through specific phases. Nat Neurosci 7:136-144.

Ozen I, Galichet C, Watts C, Parras C, Guillemot F, Raineteau O (2007) Proliferating neuronal progenitors in the postnatal hippocampus transiently express the proneural gene Ngn2. Eur J Neurosci 25:2591-2603.

Pleasure S, Collins A, Lowenstein D (2000) Unique expression patterns of cell fate molecules delineate sequential stages of dentate gyrus development. J Neurosci 20:6095-6105.

Pontious A, Kowalczyk T, Englund C, Hevner RF (2008) Role of intermediate progenitor cells in cerebral cortex development. Dev Neurosci 30:24-32.

Scardigli R, Bäumer N, Gruss P, Guillemot F, Le Roux I (2003) Direct and concentration-dependent regulation of the proneural gene Neurogenin2 by Pax6. Development 130:3269-3281.

Schuurmans C, Armant O, Nieto M, Stenman J, Britz O, Klenin N, Brown C, Langevin L, Seibt J, Tang H, Cunningham J, Dyck R, Walsh C, Campbell K, Polleux F, Guillemot F (2004) Sequential phases of cortical specification involve Neurogenin-dependent and -independent pathways. EMBO J 23:2892-2902.

Schwab M, Bartholomae A, Heimrich B, Feldmeyer D, Druffel-Augustin S, Goebbels S, Naya F, Zhao S, Frotscher M, Tsai M, Nave K (2000) Neuronal basic helixloop-helix proteins (NEX and BETA2/Neuro D) regulate terminal granule cell differentiation in the hippocampus. J Neurosci 20:3714-3724.

Seki T (2002) Expression patterns of immature neuronal markers PSANCAM, CRMP-4 and NeuroD in the hippocampus of young adult and aged rodents. J Neurosci Res 70:327-334.

Seki T, Namba T, Mochizuki H, Onodera M (2007) Clustering, migration, and neurite formation of neural precursor cells in the adult rat hippocampus. J Comp Neurol 502:275-290.

Seri B, García-Verdugo J, McEwen B, Alvarez-Buylla A (2001) Astrocytes give rise to new neurons in the adult mammalian hippocampus. J Neurosci 21:7153-7160.

Seri B, García-Verdugo J, Collado-Morente L, McEwen B, Alvarez-Buylla A (2004) Cell types, lineage, and architecture of the germinal zone in the adult dentate gyrus. J Comp Neurol 478:359-378.

Shen L, Nam H, Song P, Moore H, Anderson S (2006) FoxG1 haploinsufficiency results in impaired neurogenesis in the postnatal hippocampus and contextual memory deficits. Hippocampus 16:875-890.

Shi Y, Chichung Lie D, Taupin P, Nakashima K, Ray J, Yu R, Gage F, Evans R (2004) Expression and function of orphan nuclear receptor TLX in adult neural stem cells. Nature 427:78-83.

Song H, Kempermann G, Overstreet Wadiche L, Zhao C, Schinder A, Bischofberger J (2005) New neurons in the adult mammalian brain: synaptogenesis and functional integration. J Neurosci 25:10366-10368.

Steiner B, Kronenberg G, Jessberger S, Brandt M, Reuter K, Kempermann G (2004) Differential regulation of gliogenesis in the context of adult hippocampal neurogenesis in mice. Glia 46:41-52.

Steiner B, Klempin F, Wang L, Kott M, Kettenmann H, Kempermann G (2006) Type-2 cells as link between glial and neuronal lineage in adult hippocampal neurogenesis. Glia 54:805-814.

Tashiro A, Makino H, Gage F (2007) Experience-specific functional modification of the dentate gyrus through adult neurogenesis: a critical period during an immature stage. J Neurosci 27:3252-3259.

van Praag H, Kempermann G, Gage F (1999) Running increases cell proliferation and neurogenesis in the adult mouse dentate gyrus. Nat Neurosci 2:266-270.

Wang J, Harris W (2005) The role of combinational coding by homeodomain and bHLH transcription factors in retinal cell fate specification. Dev Biol 285:101-115.

Williams R, Rakic P (1988) Three-dimensional counting: an accurate and direct method to estimate numbers of cells in sectioned material. J Comp Neurol 278:344-352. 